\title{
Simultaneous Adsorption and Photocatalytic Degradation of Malachite Green Using Electrospun $\mathbf{P}(3 \mathrm{HB})-\mathrm{TiO}_{2}$ Nanocomposite Fibers and Films
}

\author{
Nanthini Sridewi, Yan-Fen Lee, and Kumar Sudesh \\ Ecobiomaterial Research Laboratory, School of Biological Sciences, Universiti Sains Malaysia, Penang 11800, Malaysia \\ Correspondence should be addressed to Kumar Sudesh, ksudesh@usm.my
}

Received 9 March 2011; Accepted 2 June 2011

Academic Editor: Mohamed Sabry Abdel-Mottaleb

Copyright ( $) 2011$ Nanthini Sridewi et al. This is an open access article distributed under the Creative Commons Attribution License, which permits unrestricted use, distribution, and reproduction in any medium, provided the original work is properly cited.

\begin{abstract}
This paper demonstrated the applicability of electrospun $\mathrm{P}(3 \mathrm{HB})$ film as a dye adsorbent agent. Malachite green $(\mathrm{MG})$ was used as the model dye in this study. Interestingly, the electrospun $\mathrm{P}(3 \mathrm{HB})$ film exhibited excellent dye adsorption capacity whereby $78 \%$ of dye was adsorbed from a $30 \mu \mathrm{M}$ solution of MG. The film was further improvised by incorporating titanium dioxide photocatalysts to form a dual dye treatment system employing adsorption and photocatalytic degradation techniques. The resultant electrospun $\mathrm{P}(3 \mathrm{HB})-50 \mathrm{wt} \% \mathrm{TiO}_{2}$ was capable of completely decolorizing $\mathrm{MG}$ in 45 min under solar irradiation, which corresponded to $58.7 \%$ COD removal. The fully decolorized MG solution also proved to be nontoxic against A. aegypti mosquito larvae. The reapplicability of this film was possible as it induced a decolorization rate of $98 \%$ or more at every usage for ten consequent usages. EDX analysis suggested that there were no significant changes in the concentration of titanium ( $\mathrm{Ti}$ ) in the film before and after ten times of usage. The concentration of $\mathrm{Ti}$ in cast $\mathrm{P}(3 \mathrm{HB})-50 \mathrm{wt} \% \mathrm{TiO}_{2}$ film was found to decrease significantly during the repeated usage. The electrospun $\mathrm{P}(3 \mathrm{HB})-50 \mathrm{wt} \% \mathrm{TiO}_{2}$ film has high potency as an efficient and inexpensive yet simple method for the dye effluent decolorization, degradation, and detoxification.
\end{abstract}

\section{Introduction}

Polyhydroxyalkanoate (PHA) is a biodegradable polyester that has gained much commercial interest over the years due to its thermoplastic, nontoxic, and renewable nature [1]. PHAs are stored intracellularly as energy storage inclusions by various bacteria during environmental stress [2-9]. Of all the known PHAs, poly-3-hydroxybutyrate $(\mathrm{P}(3 \mathrm{HB}))$ is the most common and widely studied. This highly crystalline polymer is synthesized by a large number of Gram-negative and Gram-positive bacteria $[10,11]$.

In line with the ability of $\mathrm{P}(3 \mathrm{HB})$ to absorb oil [12], it was hypothesized that it might also possess the ability to form physical adsorption with dye molecules via hydrophobic interaction or simple Van der Waals. Our preliminary investigations proved this hypothesis to be true. Cast $\mathrm{P}(3 \mathrm{HB})$ film was found to adsorb standard dyes such as methylene blue and rose bengale. This intrigued us to further study the dye adsorption capacity of $\mathrm{P}(3 \mathrm{HB})$ film. It is evident from previous studies that the surface area of adsorbent plays a key role in determining the degree of adsorption $[13,14]$. Therefore, electrospinning technique was adopted to fabricate nanofibrous $\mathrm{P}(3 \mathrm{HB})$ film with high surface area to volume ratio. It generates ultrathin fibers when an electric field is applied to overcome the surface tension of a drop of polymer solution. A solution jet is ejected towards the collector as the electric field intensifies. Nanofibers are formed upon the evaporation of the polymer solvent [1517].

Although adsorption is an efficient method for dye effluent treatment, it merely transfers the dye molecules from its aqueous phase to a solid phase and generates secondary pollution [18]. Photocatalytic degradation of the adsorbate via advanced oxidation process could offer a complete solution for the removal and breakdown of dye pollutants for a more effective treatment. Therefore we incorporated $\mathrm{TiO}_{2}$ photocatalysts into the electrospun $\mathrm{P}(3 \mathrm{HB})$ fibers to form a film with dual treatment capability, that is, adsorption and 
photocatalytic oxidation. $\mathrm{TiO}_{2}$ shows efficient catalytic efficiency and is chemically stable, cheap, and nontoxic $[19,20]$. However, the recovery of this photocatalyst from its aqueous suspension is an expensive and time-consuming process [21]. The $\mathrm{P}(3 \mathrm{HB})-\mathrm{TiO}_{2}$ composite film can altogether solve this problem by immobilizing the photocatalyst onto $\mathrm{P}(3 \mathrm{HB})$ polymer matrix and allow its reapplication.

The model dye used in this study is Malachite green (MG), a triphenylmethane dye. MG has been used extensively in the leather, paper, silk, cotton, and jute dyeing processes. It is also used as an antifungal and antiprotozoan agent in fisheries and aquaculture industry [22, 23]. However, MG and its metabolites are known to cause mutagenic, carcinogenic, and teratogenic effects to living organisms [24]. Therefore it is crucial to completely remove this dye pollutant from the industrial effluents before entering the aquatic system. Various researches on MG adsorption using solid materials such as tamarind fruit shell [25], hen feathers [26], rice straw-derived char [27], lemon peel [28], and activated carbon [29] have been documented thus far.

In the current research, we are presenting the simultaneous adsorption and degradation of $\mathrm{MG}$ via $\mathrm{P}(3 \mathrm{HB})-50 \mathrm{wt} \%$ $\mathrm{TiO}_{2}$ electrospun film. The ability of $\mathrm{MG}$ adsorption by electrospun $\mathrm{P}(3 \mathrm{HB})$ was tested followed by photocatalytic experiments using electrospun $\mathrm{P}(3 \mathrm{HB})-50 \mathrm{wt} \% \mathrm{TiO}_{2}$ film. The reusability of the film in dye decolorization was also analyzed. The treated MG solution was subjected to chemical oxygen demand (COD) removal analysis and toxicity evaluation.

\section{Experimental}

2.1. Materials. $\mathrm{P}(3 \mathrm{HB})(600,000 \mathrm{Da})$ was provided by $\mathrm{PHB}$ Industrial S/A, Brazil. The polymer was purified according to methods in [30]. Anatase form of $\mathrm{TiO}_{2}$ (P-25) was provided by JJ Degussa Co., Malaysia. Chloroform $\left(\mathrm{CHCl}_{3}\right)$ and dimethylformamide (DMF) solvents of analytical grade were purchased from Sigma-Aldrich, Malaysia. The chemicals were used without further purification. MG solution (Mw: 364.90; Sigma-Aldrich) was diluted to $1000 \mathrm{x}$ before being used in the photocatalytic decolorization experiments.

\subsection{Fabrication of $\mathrm{P}(3 \mathrm{HB})$ and $\mathrm{P}(3 \mathrm{HB})-\mathrm{TiO}_{2}$ Electrospun} Films. $\mathrm{P}(3 \mathrm{HB})(4 \mathrm{w} / \mathrm{v} \%)$ precursor solution was prepared by dissolving $4 \mathrm{~g}$ of the polymer in $100 \mathrm{~mL}$ of $\mathrm{CHCl}_{3} / \mathrm{DMF}$ mixed solvent at $8: 2$ ratio. $\mathrm{P}(3 \mathrm{HB})-\mathrm{TiO}_{2}$ precursor solution was prepared by dissolving $4 \mathrm{~g}$ of $\mathrm{TiO}_{2}$ powder in a similar $100 \mathrm{~mL}$ of $4 \mathrm{w} / \mathrm{v} \% \mathrm{P}(3 \mathrm{HB})$ solution. Schott bottles with precursors containing $\mathrm{TiO}_{2}$ were covered with aluminium foil during preparation and storage. The prepared solutions were magnetically stirred for 2 days at room temperature to reach homogeneity. These solutions were then heat-stirred at $55^{\circ} \mathrm{C}$ for $2 \mathrm{~h}$ prior to electrospinning. Electrospinning process was executed using Esprayer ES-2000 (Fuence, Co. Ltd., Japan) at an applied voltage and extrusion rate of

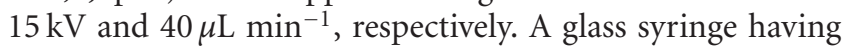
an inner needle diameter of $0.5 \mathrm{~mm}$ diameter was used to load the precursor solutions. The distance between collector to needle tip was fixed at $20 \mathrm{~cm}$. The electrospun fibers were deposited on an area of $5 \mathrm{~cm}$ diameter on the copper collecting plate. Each film was formed by electrospinning $5 \mathrm{~mL}$ of the respective precursor solution. All films were vacuum dried for a day to remove residual solvent and stored in the dark prior to usage in photocatalytic experiments. Figure 1(a) exhibits the surface morphology of electrospun $\mathrm{P}(3 \mathrm{HB})-\mathrm{TiO}_{2}$ electrospun film.

2.3. Fabrication of $\mathrm{P}(3 \mathrm{HB})$ and $\mathrm{P}(3 \mathrm{HB})-\mathrm{TiO}_{2}$ Solvent Cast Films. For each $\mathrm{P}(3 \mathrm{HB})$ film, $10 \mathrm{~mL}$ of $\mathrm{CHCl}_{3}$ was used to dissolve $0.2 \mathrm{~g}$ of $\mathrm{P}(3 \mathrm{HB})$ polymer. The solution was magnetically stirred at room temperature for 2 days and subsequently heated at $55^{\circ} \mathrm{C}$ for $2 \mathrm{~h}$. The solution was then poured into a glass Petri dish $(5 \mathrm{~cm}$ diameter) and covered with perforated aluminium foil. The Petri dish was then kept in the dark at room temperature. Cast $\mathrm{P}(3 \mathrm{HB})$ film was formed upon complete evaporation of the solvent. Similarly, $0.2 \mathrm{~g}$ of $\mathrm{TiO}_{2}$ and $0.2 \mathrm{~g}$ of $\mathrm{P}(3 \mathrm{HB})$ were added into $10 \mathrm{~mL}$ of $\mathrm{CHCl}_{3}$ to cast $\mathrm{P}(3 \mathrm{HB})-50 \mathrm{wt} \% \mathrm{TiO}_{2}$ film. The cast films were vacuum dried for a day and stored in the dark until later use. Figure 1 (b) exhibits the surface morphology of cast $\mathrm{P}(3 \mathrm{HB})$ $\mathrm{TiO}_{2}$ film.

2.4. Characterization. The morphology of the electrospun nanofibers was viewed under Leo Supra $50 \mathrm{VP}$ scanning electron microscope (SEM). The samples were mounted on aluminium stubs, sputter-coated with gold for $15 \mathrm{sec}$, and observed under SEM at an acceleration voltage of $5 \mathrm{kV}$. SEM micrographs of 5,000x magnification were used to determine mean fiber diameter via Image Analyzer. A total of 100 fibers were measured to determine the mean fiber diameter. Oxford INCA 400 Energy dispersive X-ray (EDX) Microanalysis System was used to analyze the elemental distribution on both the cast and electrospun $\mathrm{P}(3 \mathrm{HB})-50 \mathrm{wt} \% \mathrm{TiO}_{2}$ films.

\subsection{Decolorization of MG via Adsorption, Photocatalytic} Degradation, and Photolysis. The MG solution was diluted to 1000x using distilled water. Petri dishes containing the fabricated electrospun and cast $\mathrm{P}(3 \mathrm{HB})-\mathrm{TiO}_{2}$ films were filled with $15 \mathrm{~mL}$ of the diluted MG solution each. Dye adsorption analysis was studied by incubating these Petri dishes in the dark. Similar set of experiments were conducted by exposing the Petri dish to 3 different conditions, that is, solar irradiation, UV illumination, and fluorescent illumination. The source of UV illumination was from four $20 \mathrm{~W}$ black light tubes $(\lambda=365 \mathrm{~nm})$. The photocatalytic reaction system was sampled at $15 \mathrm{~min}$ intervals for $2 \mathrm{~h}$. The self-photolysis of MG was evaluated by exposing a Petri dish containing $15 \mathrm{~mL}$ of MG solution to sunlight in the absence of any film. The absorbance values of the initial MG solution $\left(\mathrm{Abs}_{\text {init }}\right)$ and periodically withdrawn samples $\left(\mathrm{Abs}_{\text {sample }}\right)$ were determined at $615 \mathrm{~nm}$ using a Jenway $6505 \mathrm{UV}$-Vis spectrophotometer. The solar light intensity was measured using Lux Meter ISOTECH ILM350. The decolorization efficiency was expressed as

$$
\frac{\left(\mathrm{Abs}_{\text {init }}-\mathrm{Abs}_{\text {sample }}\right)}{\left(\mathrm{Abs}_{\text {init }}\right)} \times 100=\text { Colour Removal }(\%) .
$$




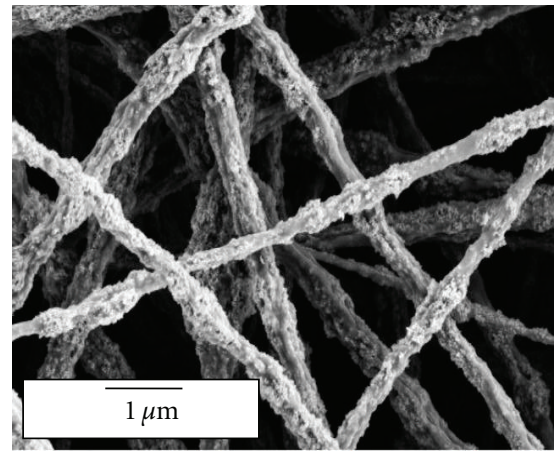

(a)

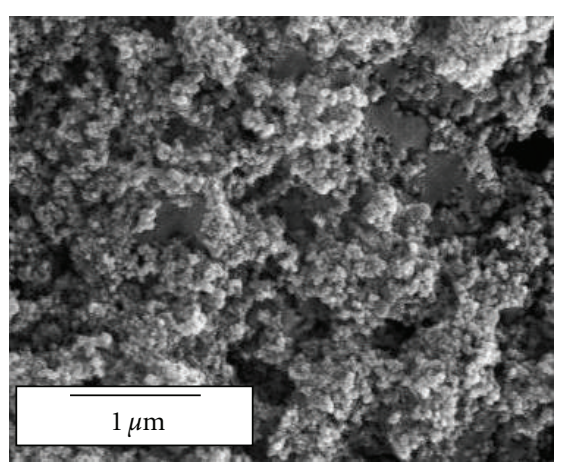

(b)

FIGURE 1: SEM micrographs showing morphological features of (a) electrospun and (b) cast $\mathrm{P}(3 \mathrm{HB})-\mathrm{TiO}_{2}$ film.

\begin{abstract}
2.6. Evaluation of $C O D$ Removal in $M G$ Treated Using $\mathrm{P}(3 \mathrm{HB})-\mathrm{TiO}_{2}$ Nanocomposite Films. MG solutions subjected to solar photocatalytic decolorization in the presence of electrospun $\mathrm{P}(3 \mathrm{HB})-50 \mathrm{wt} \% \mathrm{TiO}_{2}$ were sampled at every $15 \mathrm{~min}$ intervals for $2 \mathrm{~h}$. The samples were filtered using $0.22 \mu \mathrm{m}$ polytetrafluoroethylene (PTFE) membrane filters (Fisher Scientific). The COD values of the samples were determined by closed reflux and colorimetric technique according to the procedures in Standard Methods, Method No. 5220D [31]. Three milliliters of COD reagent and a small amount of mercury sulphate were added to every $2 \mathrm{~mL}$ of sample. Sample digestion was done in a COD reactor $(\mathrm{HACH})$ at $150^{\circ} \mathrm{C}$ for $2 \mathrm{~h}$. The samples were then cooled to reach room temperature. A HACH DR/2010 spectrophotometer was used to measure the COD value of the samples at $620 \mathrm{~nm}$.
\end{abstract}

2.7. Toxicity Assay. Several batches of MG solution treated with electrospun $\mathrm{P}(3 \mathrm{HB})-50 \mathrm{wt} \% \mathrm{TiO}_{2}$ were collected after $45 \mathrm{~min}$ of solar exposure for toxicity assay. Mosquito larvae, A. aegypti, were provided by the Vector Control Research Unit, School of Biological Sciences, Universiti Sains Malaysia. Twenty larvae from the third instar stage were transferred into paper cups containing $100 \mathrm{~mL}$ of the treated MG solution. Similarly, twenty larvae were transferred into cups containing untreated MG solution and dechlorinated tap water (control) each. The test organisms were fed on alternate days and reared under controlled laboratory conditions $\left(25^{\circ} \mathrm{C}\right.$ and 18:6 light: dark photocycle). The mortality/survival of larvae and their transformation into pupae and adults were monitored for 14 days [32]. The toxicity assay was carried out in triplicate experiments and expressed as mean \pm standard deviation (SD).

\section{Results and Discussion}

3.1. Adsorption Analysis. The ability of cast and electrospun $\mathrm{P}(3 \mathrm{HB})$ films to adsorb $\mathrm{MG}$ dye molecules were tested in the absence of light (Figure 2). As expected both $\mathrm{P}(3 \mathrm{HB})$ films were able to adsorb the dye from the MG solution. The electrospun $\mathrm{P}(3 \mathrm{HB})$ film removed almost $78 \%$ of colour whereas cast $\mathrm{P}(3 \mathrm{HB})$ film removed approximately $24 \%$ of the

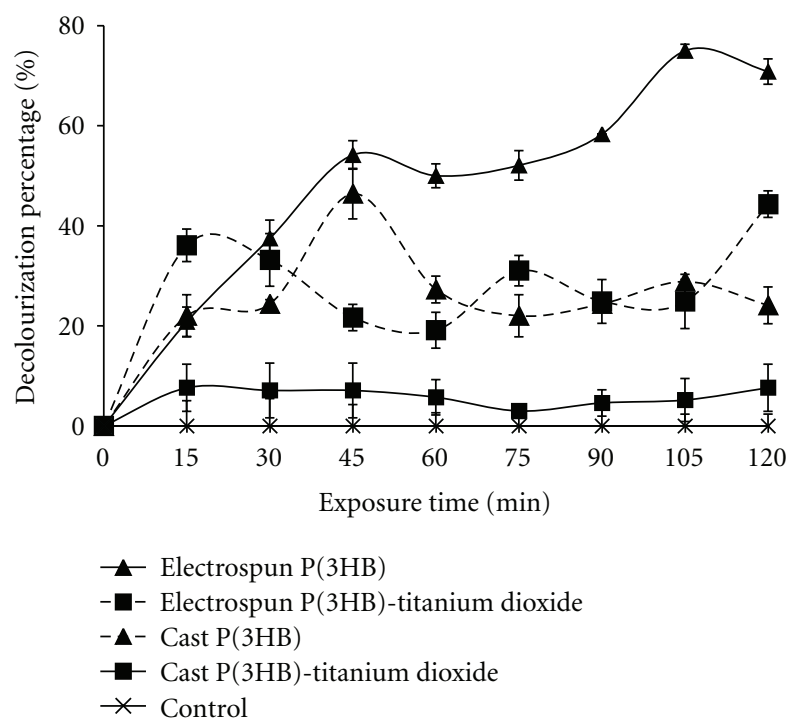

FIGURE 2: The decolorization percentage of $M G$ via adsorption process over time using cast and electrospun $\mathrm{P}(3 \mathrm{HB})$ and $\mathrm{P}(3 \mathrm{HB})$ $50 \mathrm{wt} \% \mathrm{TiO}_{2}$ film.

MG dye from the solution. The availability of surface area is one of the key aspects in the adsorption process for decolorization of the dye solution. According to Gupta and Suhas [33], a good adsorbent ought to possess high porosity and large surface area so that adsorption equilibrium could be reached in shorter time. It has been well documented in the literature that electrospinning process produces nanofibrous network with high porosity, open 3D structure and high surface area to volume ratio [34-36]. Electrospun nanofibers are reported to have surface area which is approximately 12 orders of magnitude more than thin films [37]. In this study, the electrospun films exhibited almost 3-4 orders of magnitude more dye adsorption capacity as compared to cast films. These attributes coupled with the hydrophobic nature of the electrospun $\mathrm{P}(3 \mathrm{HB})$ nanofibers made it an excellent adsorbent for MG. However, it should be noted that adsorption is merely a form of phase conversion of the dye pollutant [18]. Thus, $\mathrm{TiO}_{2}$ photocatalysts were 


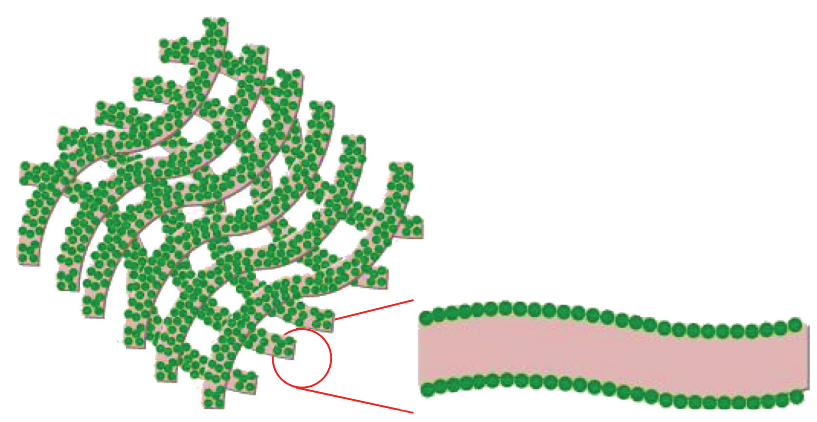

(a)
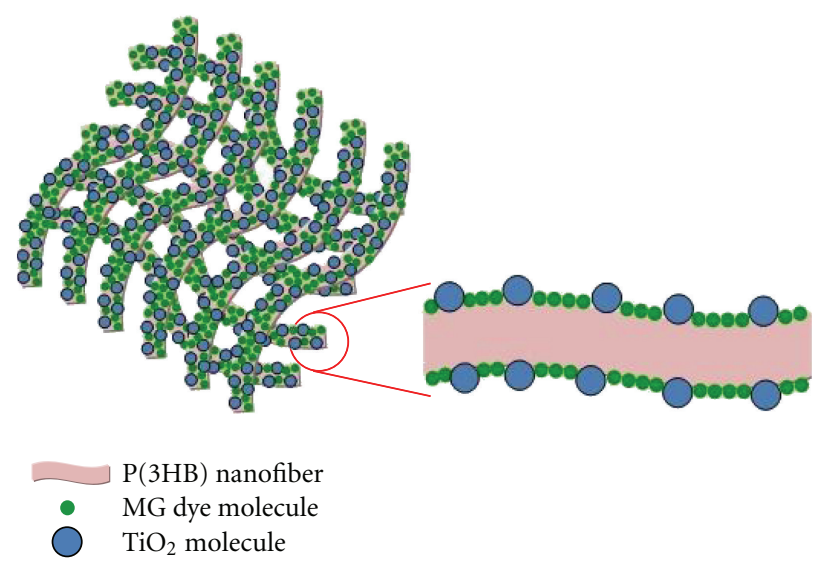

(b)

FIGURE 3: Schematics showing the proposed mechanism involved in the MG dye molecules adsorption onto electrospun (a) $\mathrm{P}(3 \mathrm{HB})$ and (b) $\mathrm{P}(3 \mathrm{HB})-50 \mathrm{wt} \% \mathrm{TiO}_{2}$ film.

incorporated into the ultrathin $\mathrm{P}(3 \mathrm{HB})$ fibers in order to combine both adsorption and advanced oxidation process (AOP) in a single system. In addition, the immobilization of $\mathrm{TiO}_{2}$ also circumvents the cost and time involved in the photocatalysts recovery process [21]. In the presence of $\mathrm{TiO}_{2}$, the overall MG dye adsorption capacity of the films decreased. The electrospun and cast $\mathrm{P}(3 \mathrm{HB})-50 \mathrm{wt} \% \mathrm{TiO}_{2}$ films only decolorized approximately 40 and $15 \%$ of the dye, respectively. Two possible reasons for the observed trend could be (i) the reduced surface area of $\mathrm{P}(3 \mathrm{HB})$ substrate due to the presence of photocatalysts and (ii) the surface nature of $\mathrm{TiO}_{2}$ which repelled the cationic MG dye molecules [38]. The possible mechanism involved in the adsorption of MG dye molecules on electrospun $\mathrm{P}(3 \mathrm{HB})$ and $\mathrm{P}(3 \mathrm{HB})-\mathrm{TiO}_{2}$ films is illustrated in Figure 3. According to Bergamini et al. [39], some dye molecules do not adsorb onto $\mathrm{TiO}_{2}$ surface. The authors reported that the adsorption of Yellow 3, Red 51, and Blue 74 on $\mathrm{TiO}_{2}$ surface was almost negligible. The $\mathrm{P}(3 \mathrm{HB})-\mathrm{TiO}_{2}$ composite films could aid in bringing such dye molecules closer to the $\mathrm{TiO}_{2}$ surface by adsorbing onto the $\mathrm{P}(3 \mathrm{HB})$ polymer matrix to be degraded photocatalytically.

3.2. Photolysis and Photocatalytic Decolorization of MG under Various Light Sources. The decolorization efficiency of MG was in the order of electrospun $\mathrm{P}(3 \mathrm{HB})-50 \mathrm{wt} \% \mathrm{TiO}_{2}>$ cast
$\mathrm{P}(3 \mathrm{HB})-50 \mathrm{wt} \% \mathrm{TiO}_{2}>$ electrospun $\mathrm{P}(3 \mathrm{HB})>$ cast $\mathrm{P}(3 \mathrm{HB})$ under all the different light sources (Figure 4 ). The synergistic effect of adsorption and photocatalytic degradation processes taking place on the $\mathrm{P}(3 \mathrm{HB})-50 \mathrm{wt} \% \mathrm{TiO}_{2}$ films enabled it to more effectively decolorize $\mathrm{MG}$ as compared to $\mathrm{P}(3 \mathrm{HB})$ films under irradiation. When $\mathrm{TiO}_{2}$ particles are irradiated by UV light, electrons of the valence band are transferred across the band gap into the conduction band, creating electron/hole pair which then diffuses to the $\mathrm{TiO}_{2}$ surface. They will react with water and surface hydroxide ions to produce hydroxyl radicals $(\cdot \mathrm{OH})$ whereas the electrons will react with adsorbed $\mathrm{O}_{2}$ to produce superoxide radicals [40-43]. These radicals are strong oxidizing agents but do not travel very far from the active centre of the photocatalyst [44]. The adsorption of $\mathrm{MG}$ molecules on the $\mathrm{P}(3 \mathrm{HB})$ matrix could have allowed more dye substrate to be in proximity with these radicals and enhanced the overall dye decolorization rate. It could be reasonably inferred that the aforementioned mechanism had undermined the effect of poor adsorbance of $\mathrm{MG}$ onto $\mathrm{TiO}_{2}$ particles. In general, the mechanism of photocatalytic decolorization of the dye using $\mathrm{P}(3 \mathrm{HB})-\mathrm{TiO}_{2}$ films is presumed to follow the following steps: (i) migration of MG dye molecules in the fluid phase to the interface region of $\mathrm{P}(3 \mathrm{HB})-\mathrm{TiO}_{2}$ film, (ii) adsorption of the MG dye molecules onto $\mathrm{P}(3 \mathrm{HB})$ matrix, (iii) reaction of the adsorbed molecules with hydroxyl/superoxide radicals, (iv) desorption of the degradation products, and (v) removal of degradation products from the interface region. It is worth noting that a major drawback in $\mathrm{TiO}_{2}$ photocatalysis is the rapid recombination of electron-hole pair which reduces the quantum yield of photocatalytic process. Kedem et al. [45] reported that the migration of photogenerated electrons from $\mathrm{TiO}_{2}$ particles to inert domains suppresses the recombination of electron-hole pairs, hence, photocatalytic activity is enhanced. A more detailed study, however, is needed to prove such electron scavenging ability of $\mathrm{P}(3 \mathrm{HB})$ domain in the $\mathrm{P}(3 \mathrm{HB})-50 \mathrm{wt} \% \mathrm{TiO}_{2}$ nanocomposite.

The electrospun $\mathrm{P}(3 \mathrm{HB})-50 \mathrm{wt} \% \mathrm{TiO}_{2}$ film exhibited decolorization efficiency at 1 to 2 orders of magnitude more than the cast film of similar composition. According to Yang et al. [46], photocatalytic activity largely depends on the contact of organic substrate with the catalyst surface and interfacial charge transfer reaction. Therefore, the porosity and high surface area of the electrospun $\mathrm{P}(3 \mathrm{HB})-50 \mathrm{wt} \%$ $\mathrm{TiO}_{2}$ might have allowed more dye molecules to be in contact with $\mathrm{TiO}_{2}$ particle surface. Additionally, the adsorption of dye molecules on the polymer matrix of $\mathrm{P}(3 \mathrm{HB})-50 \mathrm{wt} \%$ $\mathrm{TiO}_{2}$ fibers could have helped in bringing the dye molecules closer to the photocatalysts and enhanced the photocatalytic reaction altogether. The activation of photocatalysts strongly depends on the absorption of light photons by the catalysts. However, in most $\mathrm{TiO}_{2}$ based photocatalytic reaction systems, the path length of photons in the aqueous system is greatly reduced in the presence of high amount of suspended catalyst particles and dye molecules $[47,48]$. In the current method, the electrospun $\mathrm{P}(3 \mathrm{HB})-50 \mathrm{wt} \% \mathrm{TiO}_{2}$ film could facilitate more light penetration into the aqueous system by immobilizing the catalyst and adsorbing the dye molecules. Thus, more light photons will reach the reaction sites of 


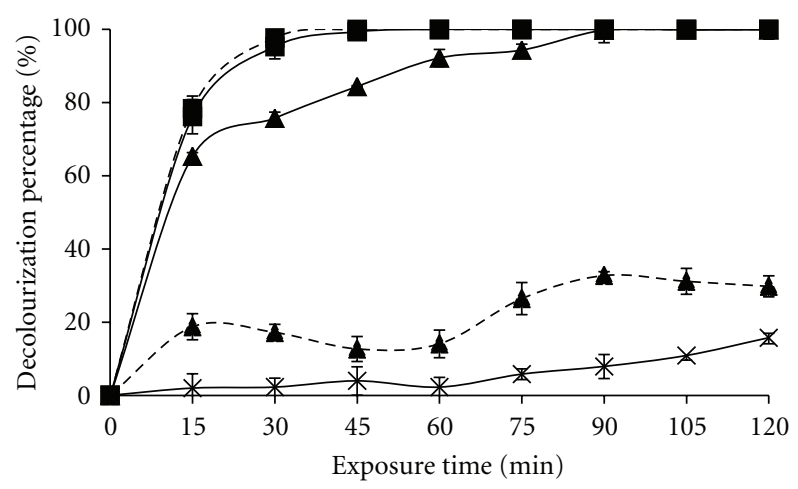

(a)

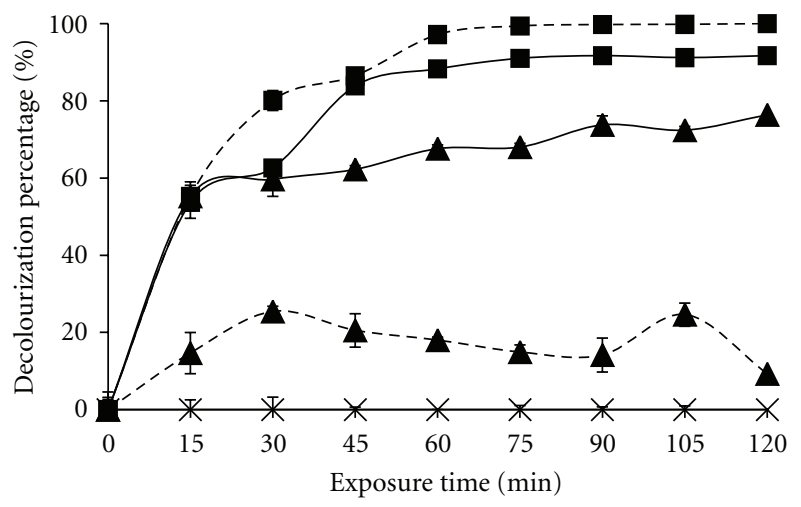

(b)

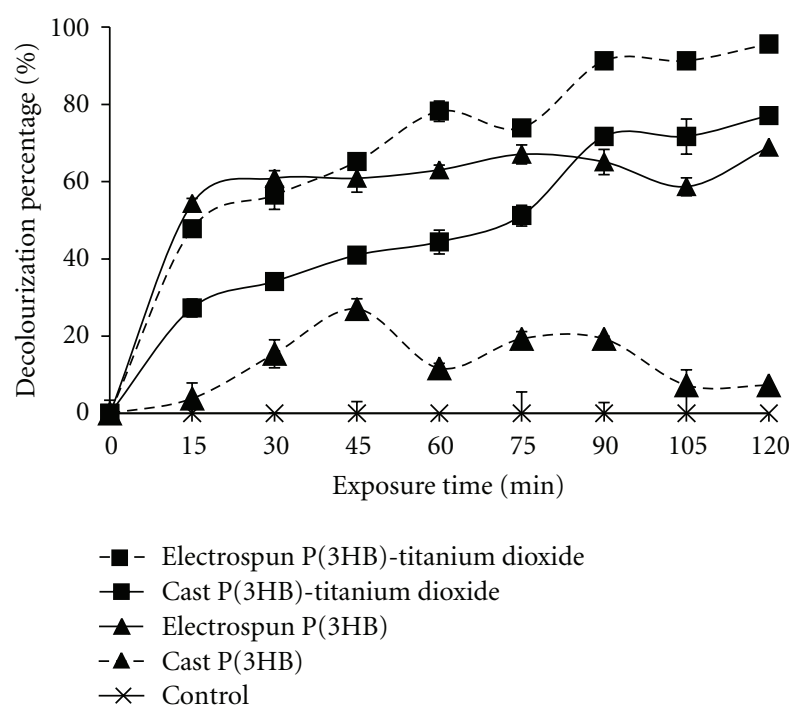

(c)

Figure 4: The decolorization percentage of $\mathrm{MG}$ over time using cast and electrospun $\mathrm{P}(3 \mathrm{HB})$ and $\mathrm{P}(3 \mathrm{HB})-50 \mathrm{wt} \% \mathrm{TiO}{ }_{2}$ film under (a) sunlight, (b) UV light, and (c) fluorescent light.

$\mathrm{TiO}_{2}$ resulting in enhanced photocatalytic reactions. As for the $\mathrm{P}(3 \mathrm{HB})$ films, electrospun films demonstrated higher decolorization rate under all the different illumination sources. Unlike the electrospun $\mathrm{P}(3 \mathrm{HB})$ film, the cast $\mathrm{P}(3 \mathrm{HB})$ films marked a fluctuating trend in $\mathrm{MG}$ decolorization indicating a constant adsorption/desorption process. It could be postulated that reversible adsorption occurs in the cast film owing to weak Van der Waals forces between the dye molecules and cast polymer surface [33]. The absence of such fluctuation in the electrospun $\mathrm{P}(3 \mathrm{HB})$ film could be attributed to the better adherence or entrapment of dye molecules on this film owing to its open porous and 3dimensional structure as compared to cast film.

The decolorization efficiency of the tested films was in the order of sunlight $>$ UV light $>$ fluorescent light. It is of interest to find that the decolorization efficiency of the films were best under sunlight when compared against UV and fluorescent light. This could be attributed to the additional contribution by self-photolysis of MG. In the absence of any film, decolorization of MG progressed slowly to reach approximately $12 \%$ at the end of $2 \mathrm{~h}$ solar exposure. MG undergoes a strong photolytic degradation reaction, resulting in the formation of highly persistent transformation products [49]. Apart from that, the increase in solution temperature during solar exposure could be another contributing factor for the rapid decolorization of $\mathrm{MG}$ under sunlight. The average temperature of MG solutions exposed to sunlight was approximately $55^{\circ} \mathrm{C}$ whereas the MG solutions treated under UV and fluorescent light were kept at room temperature $\left(25^{\circ} \mathrm{C}\right)$. According to previous studies, although the increase in reaction temperature lowers the solubility of $\mathrm{O}_{2}$ in water, the photodegradation effectiveness still increases owing to the increased collision rate of molecules in solution $[50,51]$. Electrospun and cast $\mathrm{P}(3 \mathrm{HB})-50 \mathrm{wt} \%$ $\mathrm{TiO}_{2}$ films completely decolorized MG after 45 and $60 \mathrm{~min}$ of solar irradiation, respectively. These films gained their original white color at the end of the experiment indicating breakdown of the dye component by $\mathrm{TiO}_{2}$ (Figures 5(a) and 5(b)). The electrospun $\mathrm{P}(3 \mathrm{HB})$ was also able to completely decolorize the MG dye after 90 min of solar irradiation as 


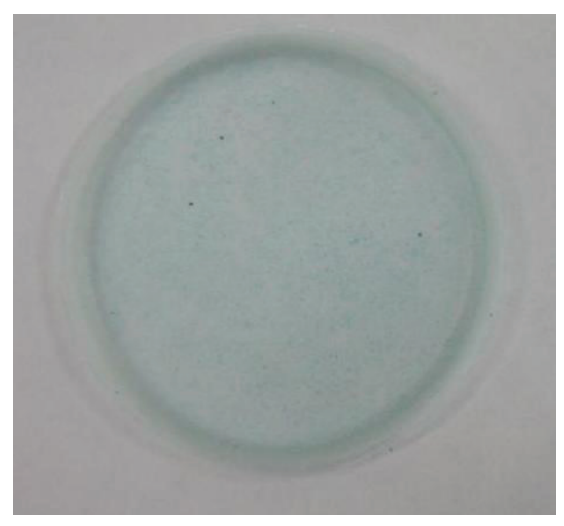

(a)

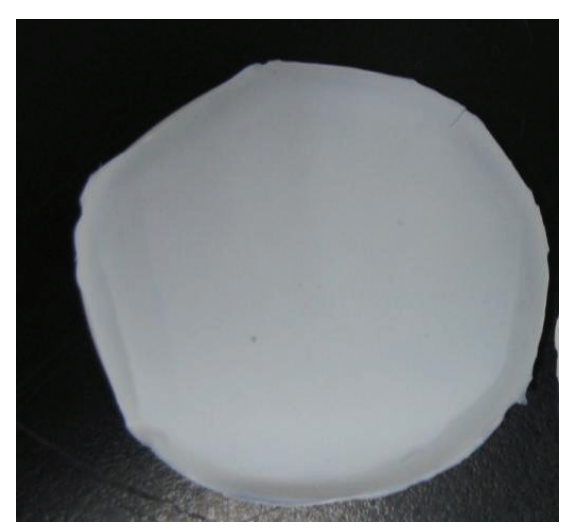

(c)

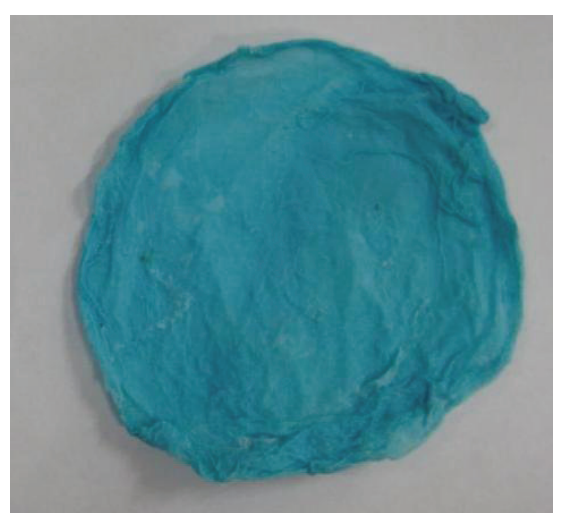

(b)

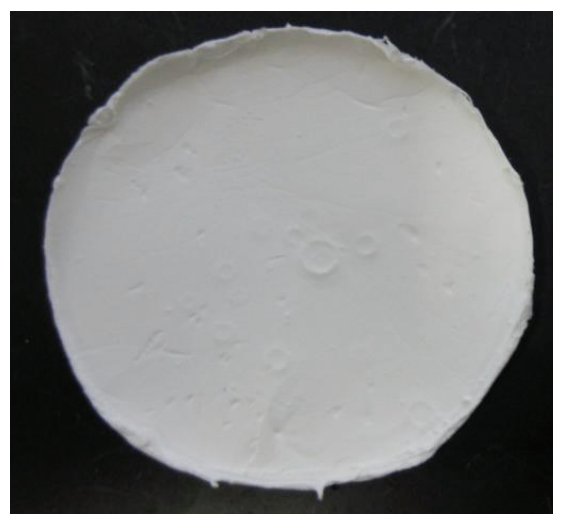

(d)

Figure 5: Digital images of (a) cast $\mathrm{P}(3 \mathrm{HB})$, (b) electrospun $\mathrm{P}(3 \mathrm{HB})$, (c) cast $\mathrm{P}(3 \mathrm{HB})-50 \mathrm{wt} \% \mathrm{TiO}_{2}$, and (d) electrospun $\mathrm{P}(3 \mathrm{HB})-50$ wt $\%$ $\mathrm{TiO}_{2}$ films, respectively, at the end of photocatalytic decolorization of MG under sunlight.

a result of both adsorption and self-photolysis of MG. Only $30 \%$ of $\mathrm{MG}$ was decolorized by cast $\mathrm{P}(3 \mathrm{HB})$ at the end of $2 \mathrm{~h}$ solar exposure. Both the electrospun and cast $\mathrm{P}(3 \mathrm{HB})$ films without $\mathrm{TiO}_{2}$ were found to retain the bluish green color of MG at the end of the experiment (Figures 5(c) and 5(d)).

3.3. COD Removal. In view of the effectiveness of the complete and rapid decolorization of $\mathrm{MG}$ using electrospun $\mathrm{P}(3 \mathrm{HB})-50 \mathrm{wt} \% \mathrm{TiO}_{2}$ films under sunlight, the degree of $\mathrm{MG}$ mineralization was evaluated via COD removal (Figure 6). It was found that the photochemical mineralization of MG showed a rapid increment, reaching a COD reduction of approximately $58.7 \%$ after $45 \mathrm{~min}$ which corresponded to $100 \%$ decolorization. The rapidness of the COD removal could be due to the synergistic effect of simultaneous adsorption and degradation of $\mathrm{MG}$ dye molecules on the surface of electrospun $\mathrm{P}(3 \mathrm{HB})-50 \mathrm{wt} \% \mathrm{TiO}_{2}$ film. However, the remaining $\mathrm{COD}$ indicates the presence of colourless metabolites in the fully decolorized MG solution. Some metabolites that are far more toxic than the parent dye compound could be generated during photocatalytic degradation process [52]. Therefore, the fully decolorized MG solution was further evaluated for its possible toxicity. However, a complete COD removal could ensure absolute mineralization of dye compound and eliminate the risk of potential toxicity. Thus, the photochemical reaction was further extended to an additional 75 min under solar irradiation. The COD value remained stable at $60 \mathrm{~min}$ but subsequently exhibited gradual decrease. At $120 \mathrm{~min}$, almost complete COD $(\sim 97.8 \%)$ removal was achieved. These findings proved the capability of the electrospun $\mathrm{P}(3 \mathrm{HB})-50 \mathrm{wt} \% \mathrm{TiO}_{2}$ film to efficiently mineralize MG dye molecules. The utilization of sunlight, good mineralization, and no sludge production via this method further strengthen its potential in dye waste treatment.

\subsection{Evaluation of the Toxic Effects of MG Solution Using A.} aegypti. MG solution that reached $100 \%$ decolorization via treatment with $\mathrm{P}(3 \mathrm{HB})-50 \mathrm{wt} \% \mathrm{TiO}_{2}$ was further analyzed for its toxicity. In this study, third instars of $A$. aegypti larvae were used as a tool to assess the toxic effects of MG and its possible by-products. A. aegypti, a macrobenthic invertebrate is the secondary consumer in a typical aquatic ecosystem [53]. It shows high sensitivity to various pollutants in water bodies such as heavy metals [54], diazinon [53], crude oil [55], and lead [56]. The feasibility of A. aegypti larvae as a bioindicator owes to its short lifespan, easy rearing, and manipulation in the laboratory [54]. The life cycle of $A$. aegypti can be completed within one and a half to three weeks depending on environmental conditions [57-59]. As 


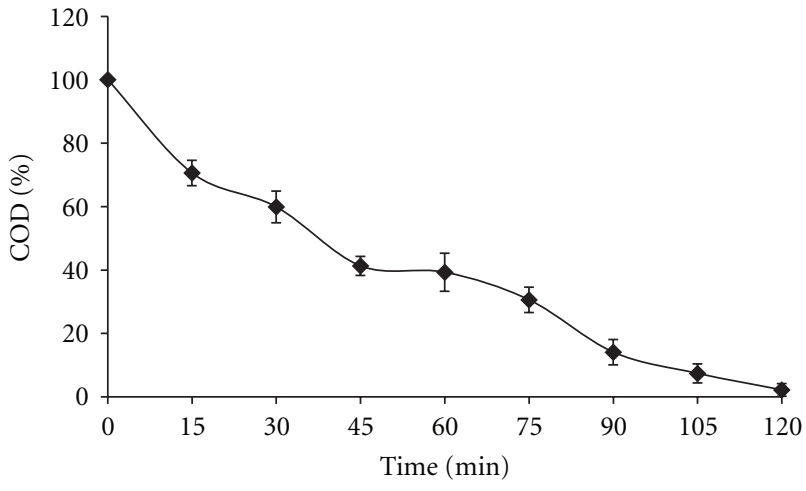

FIGURE 6: COD reduction in MG solution over time via photocatalytic degradation using electrospun $\mathrm{P}(3 \mathrm{HB})-50 \mathrm{wt} \% \mathrm{TiO}_{2}$ film under solar irradiation.

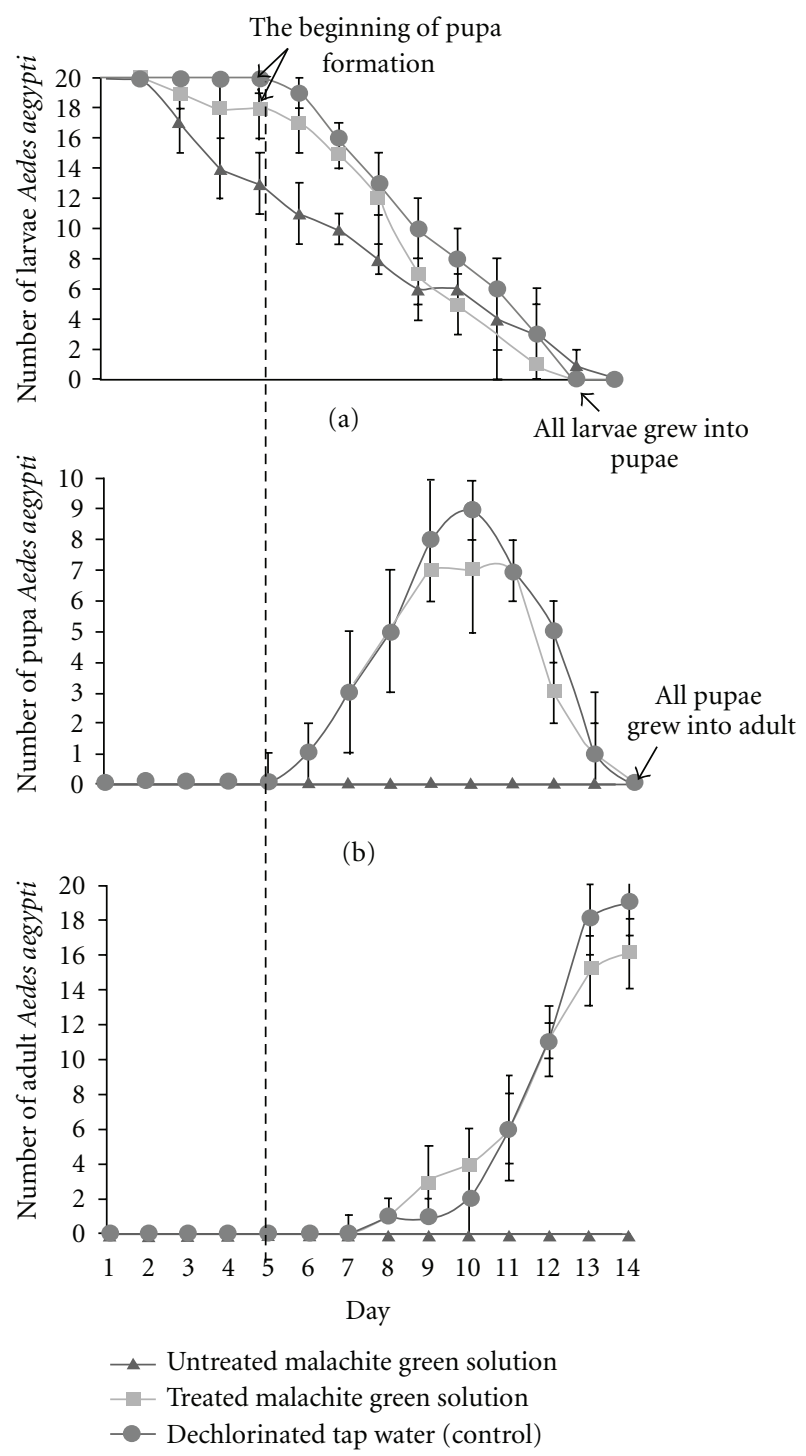

(c)

Figure 7: Survival trend of A. aegypti during stages of (a) larvae, (b) pupae, and (c) adult mosquito in untreated MG, treated MG solution, and control (dechlorinated tap water) over a period of 14 days.

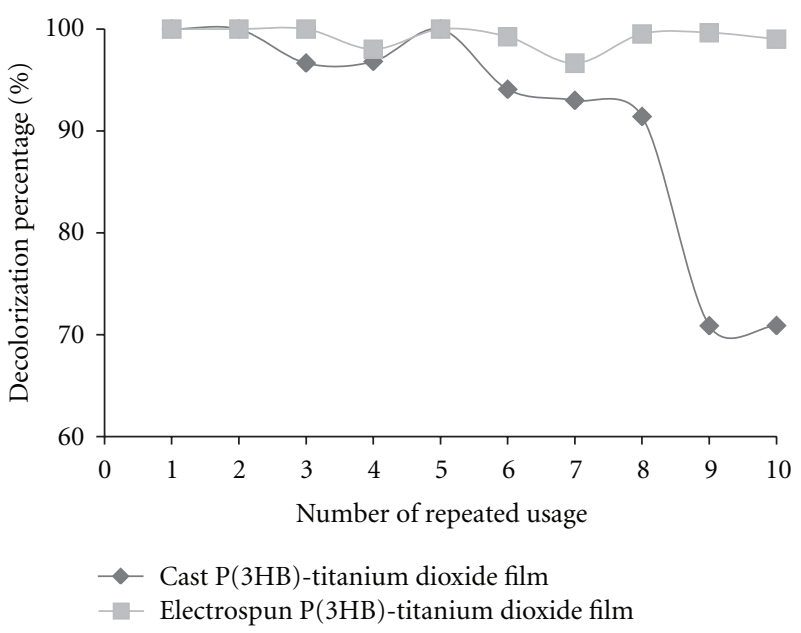

FIgUre 8: The decolorization percentage of MG in ten repeated decolorization experiments using the same electrospun and cast $\mathrm{P}(3 \mathrm{HB})-50 \mathrm{wt} \% \mathrm{TiO}_{2}$ films under solar irradiation.

revealed in Figure 7, the survival trend of A. aegypti over 14 days in decolorized MG solution and dechlorinated tap water (control) did not differ significantly. Approximately $80 \%$ and 95\% of the larvae survived at the end of the experiment, respectively. The larvae underwent normal development and no delays in the emergence of pupae and adult were observed. In contrast, the development of A. aegypti larvae in the untreated MG solution was completely retarded. The transformation of the larvae into the next growth stage (pupae) did not take place throughout the experimental period. Furthermore, the survival rate of the larvae decreased with time, reaching $100 \%$ mortality at day 14 . This indicated the deleterious effect of untreated MG on the aquatic fauna. This might implicate an ecological imbalance that could bring adverse effect on man and environment. The findings of this research suggests that the electrospun $\mathrm{P}(3 \mathrm{HB})-\mathrm{TiO}_{2}$ film could offer an efficient, yet simple method for the decolorization and also detoxification of toxic compounds like MG.

3.5. Studies on the Re-Applicability of $\mathrm{P}(3 \mathrm{HB})-\mathrm{TiO}_{2}$ Films. The electrospun and cast $\mathrm{P}(3 \mathrm{HB})-50 \mathrm{wt} \% \mathrm{TiO}_{2}$ films were tested for their re-applicability in decolorizing MG under solar irradiation. This was determined by evaluating the percentage of MG decolorization in ten consequent experiments using the same electrospun and cast film (Figure 8). The dispersion of every element on both films did not show any significant difference according to energy dispersive X-ray (EDX) (Table 1). The results obtained from decolorization experiments indicated that MG was decolorized to an extent of approximately $98.0 \%$ or more by electrospun $\mathrm{P}(3 \mathrm{HB})$ $50 \mathrm{wt} \% \mathrm{TiO}_{2}$ nanofibrous film at every round of decolorization experiment. On average, the cast $\mathrm{P}(3 \mathrm{HB})-50 \mathrm{wt} \% \mathrm{TiO}_{2}$ film showed a lower decolorization efficiency as compared to that of electrospun film. Furthermore, the decolorizing efficiency of the cast film exhibited gradual decrease from the fifth usage onwards reaching only $70.9 \%$ of decolorization 
TABLe 1: Energy dispersive X-ray (EDX) analysis on electrospun $\mathrm{P}(3 \mathrm{HB})-50 \mathrm{wt} \% \mathrm{TiO}_{2}$ and cast $\mathrm{P}(3 \mathrm{HB})-50 \mathrm{wt} \% \mathrm{TiO}{ }_{2}$ composite films after usage in ten repeated decolorization experiments.

\begin{tabular}{|c|c|c|c|c|c|c|c|c|}
\hline \multirow{4}{*}{ Element } & \multicolumn{4}{|c|}{ Electrospun $\mathrm{P}(3 \mathrm{HB})-50 \mathrm{wt} \%$} & \multicolumn{4}{|c|}{ Cast $\mathrm{P}(3 \mathrm{HB})-50 \mathrm{wt} \%$} \\
\hline & \multirow{2}{*}{\multicolumn{8}{|c|}{ Weight of element (g) }} \\
\hline & & & & & & & & \\
\hline & Before & After & $P^{*}$ value & $\%$ of decrease & Before & After & $P^{*}$ value & $\%$ of decrease \\
\hline Titanium & 0.0737 & 0.0724 & $>0.05$ & 1.76 & 0.0731 & 0.0491 & $<0.05$ & 32.83 \\
\hline Oxygen & 0.0884 & 0.0646 & $<0.05$ & 26.92 & 0.0866 & 0.0437 & $<0.05$ & 49.54 \\
\hline Carbon & 0.0516 & 0.0109 & $<0.05$ & 78.88 & 0.0506 & 0.0112 & $<0.05$ & 77.87 \\
\hline
\end{tabular}

${ }^{*}$ Note: the significance of the difference of every element before and after repeated decolorization experiments were analyzed using one-way ANOVA at $95 \%$ confidence level.

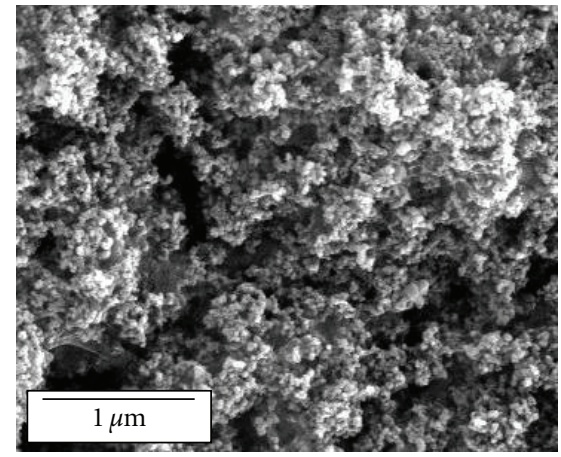

(a)

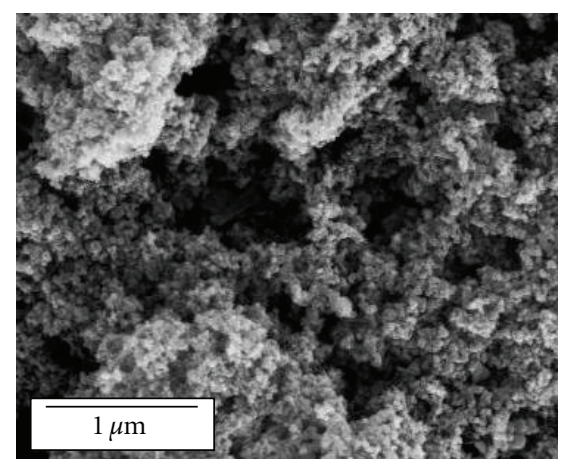

(c)

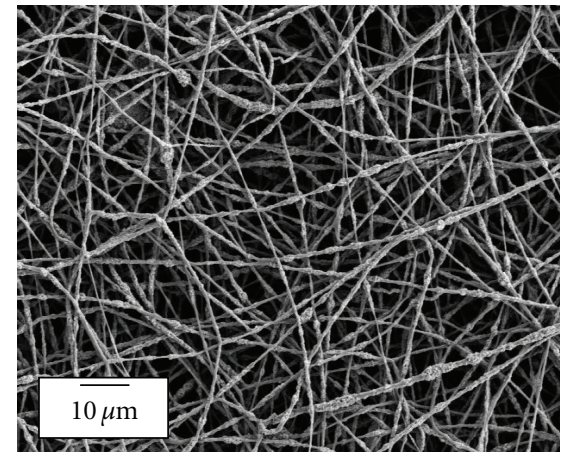

(b)

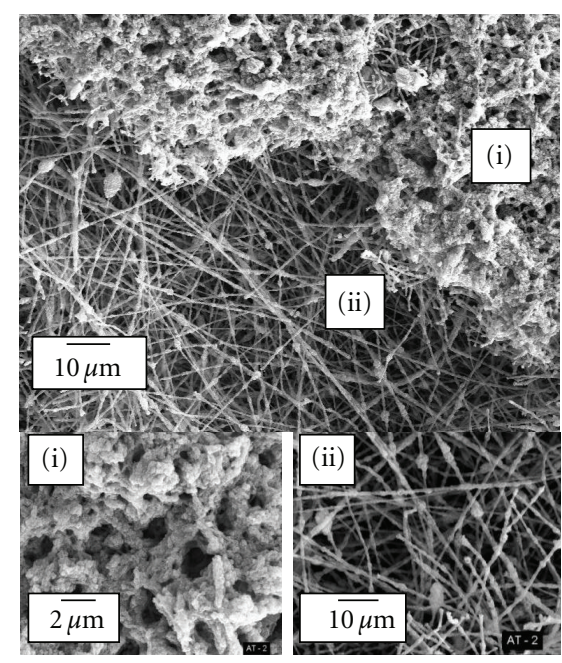

(d)

FIGURE 9: SEM micrographs showing morphological features of (a) cast and (b) electrospun $\mathrm{P}(3 \mathrm{HB})-50$ wt $\%$ TiO ${ }_{2}$ before photocatalytic decolorization experiment and (c) cast and (d) electrospun $\mathrm{P}(3 \mathrm{HB})-50 \mathrm{wt} \% \mathrm{TiO}_{2}$ after ten consequent decolorization experiments under solar irradiation.

at tenth repeated usage. Nonwoven randomly oriented nanofibers provide higher surface area to volume ratio, porosity, and 3-dimensional structure $[60,61]$. The abovementioned characteristics may contribute to higher exposure of MG dye molecules to $\mathrm{TiO}_{2}$ active sites. The intrinsic catalyst effect is also reported to be more pronounced when loaded in ultrafine fibers [62]. For these reasons, the electrospun $\mathrm{P}(3 \mathrm{HB})-50 \mathrm{wt} \% \mathrm{TiO}_{2}$ film might have exhibited higher decolorization rate throughout the repeated usages as compared to the cast film. The morphology of both films was analyzed under SEM before and after ten rounds of MG decolorization experiments (Figure 9). The electrospun $\mathrm{P}(3 \mathrm{HB})-50 \mathrm{wt} \% \mathrm{TiO}_{2}$ film exhibited dramatic changes in the fiber morphology after 10 times usage. The fibers in the upper layer were seen to be clumped together and had a distorted shape. The fibers in the inner layer retained their original fibrous structure even after the 10 consequent decolorization experiments. However, breakage of the fibers were also seen to have taken place to a certain extend. These phenomena are most likely due to the oxidative nature 
of the free radicals produced by $\mathrm{TiO}_{2}$ that could degrade organic materials [63]. Water hydrolysis could have also contributed to the decomposition of electrospun nanofibers. The high surface area to mass of electrospun film could have exposed more of the polymer matrix causing noticeable changes in its surface morphology compared to that of cast film. The surface morphology of cast $\mathrm{P}(3 \mathrm{HB})-50 \mathrm{wt} \%$ $\mathrm{TiO}_{2}$ film was not obviously different from its original form after repeated usage in ten cycles of photocatalytic experiments. But it is important to note that the cast films showed increasing weight loss after every decolorization experiment suggesting erosion of the film mass. EDX analysis on the films before and after ten repeated usages was carried out to study the changes in the elemental distribution (Table 1). It was found that there were no significant changes in the amount of titanium ( $\mathrm{Ti}$ ) and oxygen $(\mathrm{O})$ in the electrospun $\mathrm{P}(3 \mathrm{HB})-50 \mathrm{wt} \% \mathrm{TiO}_{2}$ film before and after ten repeated usages. However, there was significant difference in the weight percentage of carbon (C) in this film which could be attributed to the loss of polymer mass during the photocatalytic experiments. On the other hand, the cast film showed significant reduction in the amount of Ti and $\mathrm{C}$ after ten times usage. This might be caused by the bulk erosion of the photocatalyst containing polymer mass, which could have also contributed to the overall reduced decolorization activity.

\section{Conclusion}

The electrospun $\mathrm{P}(3 \mathrm{HB})$ film exhibited excellent adsorption capability when tested against MG. Approximately $80 \%$ of the dye was removed in less than $2 \mathrm{~h}$. The electrospun $\mathrm{P}(3 \mathrm{HB})-50 \mathrm{wt} \% \mathrm{TiO}_{2}$ gave the highest decolorization activity under solar irradiation as compared to UV and fluorescent light. This film was able to completely decolorize the MG solution under $45 \mathrm{~min}$ of solar irradiation via simultaneous adsorption and photocatalytic degradation. When the solar irradiation was prolonged for $2 \mathrm{~h}$, approximately $97.8 \%$ of COD removal was achieved in the MG solution in the presence of electrospun $\mathrm{P}(3 \mathrm{HB})-50 \mathrm{wt} \% \mathrm{TiO}_{2}$. The fully decolorized dye solution was also proved to be nontoxic to A. aegypti larvae. The electrospun $\mathrm{P}(3 \mathrm{HB})-50 \mathrm{wt} \% \mathrm{TiO}_{2}$ was also found to be re-applicable in the decolorization of $\mathrm{MG}$ solution as it decolorized MG to an extent of approximately $98.0 \%$ or more at every round for ten consequent rounds of decolorization experiment. The electrospun $\mathrm{P}(3 \mathrm{HB})-50 \mathrm{wt} \%$ $\mathrm{TiO}_{2}$ could offer a simple and cheap, yet effective method for the decolorization and detoxification of toxic dyes like MG.

\section{Acknowledgment}

The authors appreciate the technical assistance by $\mathrm{Mr}$. R. Patchamuthu and Ms. Jamilah Afandi of Electron Microscopy Unit, School of Biological Sciences during SEM analyses. The authors thank Mr. M. Nasir Hasan from the Vector Control Research Unit, School of Biological Sciences for assisting them in the toxicity test using mosquito larvae. They also thank Professor T. T. Teng from the Environmental
Technology Division, School of Industrial Technology for guiding them during COD analysis. N. Sridewi, a recipient of the National Science Foundation Fellowship, is grateful to the Ministry of Science and Technology (MOSTI) for the financial support.

\section{References}

[1] S. P. Valappil, R. Rai, C. Bucke, and I. Roy, "Polyhydroxyalkanoate biosynthesis in Bacillus cereus SPV under varied limiting conditions and an insight into the biosynthetic genes involved," Journal of Applied Microbiology, vol. 104, no. 6, pp. 1624-1635, 2008.

[2] B. Kessler and B. Witholt, "Factors involved in the regulatory network of polyhydroxyalkanoate metabolism," Journal of Biotechnology, vol. 86, no. 2, pp. 97-104, 2001.

[3] K. Lakshman and T. R. Shamala, "Extraction of polyhydroxyalkanoate from Sinorhizobium meliloti cells using Microbispora sp. culture and its enzymes," Enzyme and Microbial Technology, vol. 39, no. 7, pp. 1471-1475, 2006.

[4] M. Pijuan, C. Casas, and J. A. Baeza, "Polyhydroxyalkanoate synthesis using different carbon sources by two enhanced biological phosphorus removal microbial communities," Process Biochemistry, vol. 44, no. 1, pp. 97-105, 2009.

[5] A. A. Shah, F. Hasan, A. Hameed, and S. Ahmed, "Biological degradation of plastics: a comprehensive review," Biotechnology Advances, vol. 26, no. 3, pp. 246-265, 2008.

[6] K. Sudesh, A. Maehara, Z. Gan, T. Iwata, and Y. Doi, "Direct observation of polyhydroxyalkanoate granuleassociated-proteins on native granules and on poly(3hydroxybutyrate) single crystals by atomic force microscopy," Polymer Degradation and Stability, vol. 83, no. 2, pp. 281-287, 2004.

[7] K. Sudesh and T. Iwata, "Sustainability of biobased and biodegradable plastics," Clean-Soil, Air, Water, vol. 36, no. 56, pp. 433-442, 2008.

[8] P. Suriyamongkol, R. Weselake, S. Narine, M. Moloney, and S. Shah, "Biotechnological approaches for the production of polyhydroxyalkanoates in microorganisms and plants-a review," Biotechnology Advances, vol. 25, no. 2, pp. 148-175, 2007.

[9] S. P. Valappil, D. Peiris, G. J. Langley et al., "Polyhydroxyalkanoate (PHA) biosynthesis from structurally unrelated carbon sources by a newly characterized Bacillus spp," Journal of Biotechnology, vol. 127, no. 3, pp. 475-487, 2007.

[10] A. Manna and A. K. Paul, "Degradation of microbial polyester poly(3-hydroxybutyrate) in environmental samples and in culture," Biodegradation, vol. 11, no. 5, pp. 323-329, 2000.

[11] Y. Tokiwa and C. U. Ugwu, "Biotechnological production of (R)-3-hydroxybutyric acid monomer," Journal of Biotechnology, vol. 132, no. 3, pp. 264-272, 2007.

[12] K. Sudesh, C. Y. Loo, L. K. Goh, T. Iwata, and M. Maeda, "The oil-absorbing property of polyhydroxyalkanoate films and its practical application: a refreshing new outlook for an old degrading material," Macromolecular Bioscience, vol. 7, no. 11, pp. 1199-1205, 2007.

[13] C. Akmil-Başar, Y. Önal, T. Kiliçer, and D. Eren, "Adsorptions of high concentration malachite green by two activated carbons having different porous structures," Journal of Hazardous Materials, vol. 127, no. 1-3, pp. 73-80, 2005.

[14] E. E. Baldez, N. F. Robaina, and R. J. Cassella, "Employment of polyurethane foam for the adsorption of Methylene Blue 
in aqueous medium," Journal of Hazardous Materials, vol. 159, no. 2-3, pp. 580-586, 2008.

[15] J. W. Chen, K. F. Tseng, S. Delimartin, C. K. Lee, and M. H. Ho, "Preparation of biocompatible membranes by electrospinning," Desalination, vol. 233, no. 1-3, pp. 48-54, 2008.

[16] Z. M. Huang, Y. Z. Zhang, M. Kotaki, and S. Ramakrishna, "A review on polymer nanofibers by electrospinning and their applications in nanocomposites," Composites Science and Technology, vol. 63, no. 15, pp. 2223-2253, 2003.

[17] K. Tan and S. K. Obendorf, "Fabrication and evaluation of electrospun nanofibrous antimicrobial nylon 6 membranes," Journal of Membrane Science, vol. 305, no. 1-2, pp. 287-298, 2007.

[18] A. G. S. Prado and L. L. Costa, "Photocatalytic decouloration of malachite green dye by application of $\mathrm{TiO}_{2}$ nanotubes," Journal of Hazardous Materials, vol. 169, no. 1-3, pp. 297-301, 2009.

[19] C. H. Ao, S. C. Lee, J. Z. Yu, and J. H. Xu, "Photodegradation of formaldehyde by photocatalyst $\mathrm{TiO}_{2}$ : effects on the presences of $\mathrm{NO}, \mathrm{SO}_{2}$ and VOCs," Applied Catalysis B: Environmental, vol. 54, no. 1, pp. 41-50, 2004.

[20] I. K. Konstantinou and T. A. Albanis, " $\mathrm{TiO}_{2}$-assisted photocatalytic degradation of azo dyes in aqueous solution: kinetic and mechanistic investigations: a review," Applied Catalysis B: Environmental, vol. 49, no. 1, pp. 1-14, 2004.

[21] S. Meyer, R. Gorges, and G. Kreisel, "Preparation and characterisation of titanium dioxide films for catalytic applications generated by anodic spark deposition," Thin Solid Films, vol. 450, no. 2, pp. 276-281, 2004.

[22] N. Daneshvar, A. R. Khataee, M. H. Rasoulifard, and M. Pourhassan, "Biodegradation of dye solution containing Malachite Green: optimization of effective parameters using Taguchi method," Journal of Hazardous Materials, vol. 143, no. 1-2, pp. 214-219, 2007.

[23] T. Le Goff and S. Wood, "Production of malachite green oxalate and leucomalachite green reference materials certified for purity," Analytical and Bioanalytical Chemistry, vol. 391, no. 6, pp. 2035-2045, 2008.

[24] S. Srivastava, R. Sinha, and D. Roy, "Toxicological effects of malachite green,” Aquatic Toxicology, vol. 66, no. 3, pp. 319329, 2004.

[25] P. Saha, S. Chowdhury, S. Gupta, I. Kumar, and R. Kumar, "Assessment on the removal of malachite green using tamarind fruit shell as biosorbent," Clean-Soil, Air, Water, vol. 38, no. 5-6, pp. 437-445, 2010.

[26] A. Mittal, "Adsorption kinetics of removal of a toxic dye, Malachite Green, from wastewater by using hen feathers," Journal of Hazardous Materials, vol. 133, no. 1-3, pp. 196-202, 2006.

[27] B. H. Hameed and M. I. El-Khaiary, "Kinetics and equilibrium studies of malachite green adsorption on rice straw-derived char," Journal of Hazardous Materials, vol. 153, no. 1-2, pp. 701-708, 2008.

[28] K. V. Kumar, "Optimum sorption isotherm by linear and nonlinear methods for malachite green onto lemon peel," Dyes and Pigments, vol. 74, no. 3, pp. 595-597, 2007.

[29] R. Malik, D. S. Ramteke, and S. R. Wate, "Adsorption of malachite green on groundnut shell waste based powdered activated carbon," Waste Management, vol. 27, no. 9, pp. 1129$1138,2007$.

[30] J. A. Ramsay, E. Berger, R. Voyer, C. Chavarie, and B. A. Ramsay, "Extraction of poly-3-hydroxybutyrate using chlorinated solvents," Biotechnology Techniques, vol. 8, no. 8, pp. 589-594, 1994.

[31] A. E. Greenberg, L. S. Clesceri, and A. D. Eaton, "APHA (American Public Health Association)," in Standard Methods for the Examination of Water and Wastewater, APHA, Washington, DC, USA, 2005.

[32] Guidelines for Laboratory and Field Testing of Mosquito Larvicides, World Health Organization (WHO), Geneva, Switzerland, 2005.

[33] V. K. Gupta and Suhas, "Application of low-cost adsorbents for dye removal-a review," Journal of Environmental Management, vol. 90, no. 8, pp. 2313-2342, 2009.

[34] P. Gupta, C. Elkins, T. E. Long, and G. L. Wilkes, "Electrospinning of linear homopolymers of poly(methyl methacrylate): exploring relationships between fiber formation, viscosity, molecular weight and concentration in a good solvent," Polymer, vol. 46, no. 13, pp. 4799-4810, 2005.

[35] P. Gupta and G. L. Wilkes, "Some investigations on the fiber formation by utilizing a side-by-side bicomponent electrospinning approach," Polymer, vol. 44, no. 20, pp. 63536359, 2003.

[36] S. L. Shenoy, W. D. Bates, H. L. Frisch, and G. E. Wnek, "Role of chain entanglements on fiber formation during electrospinning of polymer solutions: good solvent, nonspecific polymer-polymer interaction limit," Polymer, vol. 46, no. 10, pp. 3372-3384, 2005.

[37] X. Zhang, S. Xu, and G. Han, "Fabrication and photocatalytic activity of $\mathrm{TiO}_{2}$ nanofiber membrane," Materials Letters, vol. 63, no. 21, pp. 1761-1763, 2009.

[38] C. C. Chen, C. S. Lu, Y. C. Chung, and J. L. Jan, "UV light induced photodegradation of malachite green on $\mathrm{TiO}_{2}$ nanoparticles," Journal of Hazardous Materials, vol. 141, no. 3 , pp. 520-528, 2007.

[39] R. B.M. Bergamini, M. Dezotti, L. R.R. De Araújo, and E. B. Azevedo, "Heterogeneous photocatalytic degradation of acid dyes In aqueous $\mathrm{TiO}_{2}$ suspensions: kinetics and toxicity," Journal of Advanced Oxidation Technologies, vol. 11, no. 2, pp. 308-315, 2008.

[40] J. C. Crittenden, Y. Zhang, D. W. Hand, D. L. Perram, and E. G. Marchand, "Solar detoxification of fuel-contaminated groundwater using fixed-bed photocatalysts," Water Environment Research, vol. 68, no. 3, pp. 270-278, 1996.

[41] K. I. Ishibashi, A. Fujishima, T. Watanabe, and K. Hashimoto, "Generation and deactivation processes of superoxide formed on $\mathrm{TiO}_{2}$ film illuminated by very weak UV light in air or water," Journal of Physical Chemistry B, vol. 104, no. 20, pp. 4934-4938, 2000.

[42] S. P. Yew, H. Y. Tang, and K. Sudesh, "Photocatalytic activity and biodegradation of polyhydroxybutyrate films containing titanium dioxide," Polymer Degradation and Stability, vol. 91, no. 8, pp. 1800-1807, 2006.

[43] N. Sridewi, L.-T. Tan, and K. Sudesh, "Solar photocatalytic decolorization and detoxification of industrial batik dye wastewater using $\mathrm{P}(3 \mathrm{HB})-\mathrm{TiO}_{2}$ nanocomposite films," Clean-Soil, Air, Water, vol. 39, no. 3, pp. 265-273, 2011.

[44] C. Minero, F. Catozzo, and E. Pelizzetti, "Role of adsorption in photocatalyzed reactions of organic molecules in aqueous $\mathrm{TiO}_{2}$ suspensions," Langmuir, vol. 8, no. 2, pp. 481-486, 1992.

[45] S. Kedem, D. Rozen, Y. Cohen, and Y. Paz, "Enhanced stability effect in composite polymeric nanofibers containing titanium dioxide and carbon nanotubes," Journal of Physical Chemistry C, vol. 113, no. 33, pp. 14893-14899, 2009. 
[46] Y. Yang, C. Zhang, Y. Xu, H. Wang, X. Li, and C. Wang, "Electrospun $\mathrm{Er}^{\mathrm{TiO}} \mathrm{T}_{2}$ nanofibrous films as efficient photocatalysts under solar simulated light," Materials Letters, vol. 64, no. 2, pp. 147-150, 2010.

[47] S. L. Orozco, C. A. Arancibia-Bulnes, and R. Suárez-Parra, "Radiation absorption and degradation of an azo dye in a hybrid photocatalytic reactor," Chemical Engineering Science, vol. 64, no. 9, pp. 2173-2185, 2009.

[48] S. K. Kansal, N. Kaur, and S. Singh, "Photocatalytic degradation of two commercial reactive dyes in aqueous phase using nanophotocatalysts," Nanoscale Research Letters, vol. 4, no. 7, pp. 709-716, 2009.

[49] L. A. Pérez-Estrada, A. Agüera, M. D. Hernando, S. Malato, and A. R. Fernández-Alba, "Photodegradation of malachite green under natural sunlight irradiation: kinetic and toxicity of the transformation products," Chemosphere, vol. 70, no. 11, pp. 2068-2075, 2008.

[50] S. Mozia, A. W. Morawski, M. Toyoda, and T. Tsumura, "Effect of process parameters on photodegradation of Acid Yellow 36 in a hybrid photocatalysis-membrane distillation system," Chemical Engineering Journal, vol. 150, no. 1, pp. 152-159, 2009.

[51] C. H. Wu, "Photodegradation of C.I. Reactive Red 2 in $\mathrm{UV} / \mathrm{TiO}_{2}$-based systems: effects of ultrasound irradiation," Journal of Hazardous Materials, vol. 167, no. 1-3, pp. 434-439, 2009.

[52] C. A. K. Gouvêa, F. Wypych, S. G. Moraes, N. Durán, N. Nagata, and P. Peralta-Zamora, "Semiconductor-assisted photocatalytic degradation of reactive dyes in aqueous solution," Chemosphere, vol. 40, no. 4, pp. 433-440, 2000.

[53] A. O. Agbon, P. C. Ofojekwu, I. S. Ezenwaka, and W. O. Alegbeleye, "Acute toxicity of diazinon on rotifers, cyclops, mosquito larvae and fish," Journal of Applied Sciences \& Environmental Management, vol. 6, pp. 18-21, 2002.

[54] A. Rayms-Keller, K. E. Olson, M. McGaw, C. Oray, J. O. Carlson, and B. J. Beaty, "Effect of heavy metals on Aedes aegypti (Diptera: Culicidae) larvae," Ecotoxicology and Environmental Safety, vol. 39, no. 1, pp. 41-47, 1998.

[55] F. O. Arimoro and K. M. Adamu, "Toxicological effects of water soluble fraction of crude oil on macrobenthic invertebrates: Chironomus and nosquito larvae," Research Journal of Environmental Toxicology, vol. 2, pp. 23-26, 2008.

[56] S. Kitvatanachai, C. Apiwathnasorn, S. Leemingsawat, W. Wongwit, and S. Tornee, "Determination of lead toxicity in Culex quinquefasciatus mosquitoes in the laboratory," Southeast Asian Journal of Tropical Medicine and Public Health, vol. 36, no. 4, pp. 862-874, 2005.

[57] C.Y. Lee, Z. Jaal, H. H. Yap, and N. L. Chong, Urban Pest Control A Malaysian Perspective, Vector Control Research Unit, Universiti Sains Malaysia, Penang, Malaysia, 2nd edition, 2003.

[58] A. E. Lenhart, M. Walle, H. Cedillo, and A. Kroeger, "Building a better ovitrap for detecting Aedes aegypti oviposition," Acta Tropica, vol. 96, no. 1, pp. 56-59, 2005.

[59] C. A. Triplehorn and N. F. Johnson, Borror and Delong's Introduction to the Study of Insects, USA Thomson Brooks, Tampa, Fla, USA, 7th edition, 2005.

[60] I. S. Chronakis, "Novel nanocomposites and nanoceramics based on polymer nanofibers using electrospinning processa review," Journal of Materials Processing Technology, vol. 167, no. 2-3, pp. 283-293, 2005.

[61] S. H. Tan, R. Inai, M. Kotaki, and S. Ramakrishna, "Systematic parameter study for ultra-fine fiber fabrication via electrospinning process," Polymer, vol. 46, no. 16, pp. 6128-6134, 2005.
[62] T. Subbiah, G. S. Bhat, R. W. Tock, S. Parameswaran, and S. S. Ramkumar, "Electrospinning of nanofibers," Journal of Applied Polymer Science, vol. 96, no. 2, pp. 557-569, 2005.

[63] A. Fujishima, T. N. Rao, and D. A. Tryk, "Titanium dioxide photocatalysis," Journal of Photochemistry and Photobiology C: Photochemistry Reviews, vol. 1, no. 1, pp. 1-21, 2000. 


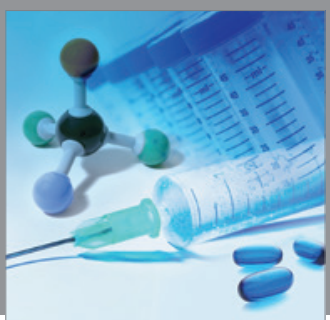

International Journal of

Medicinal Chemistry

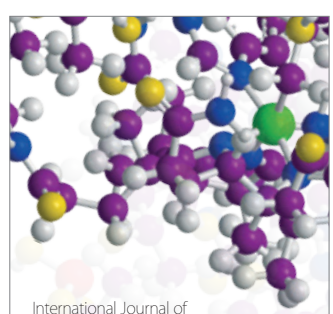

Carbohydrate Chemistry

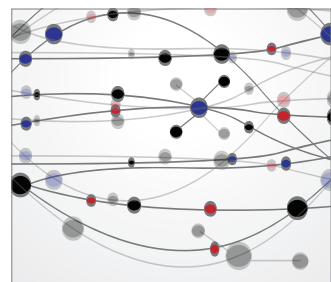

The Scientific World Journal
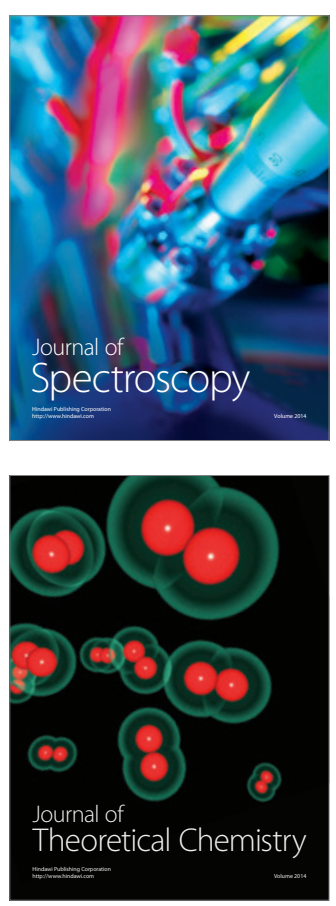
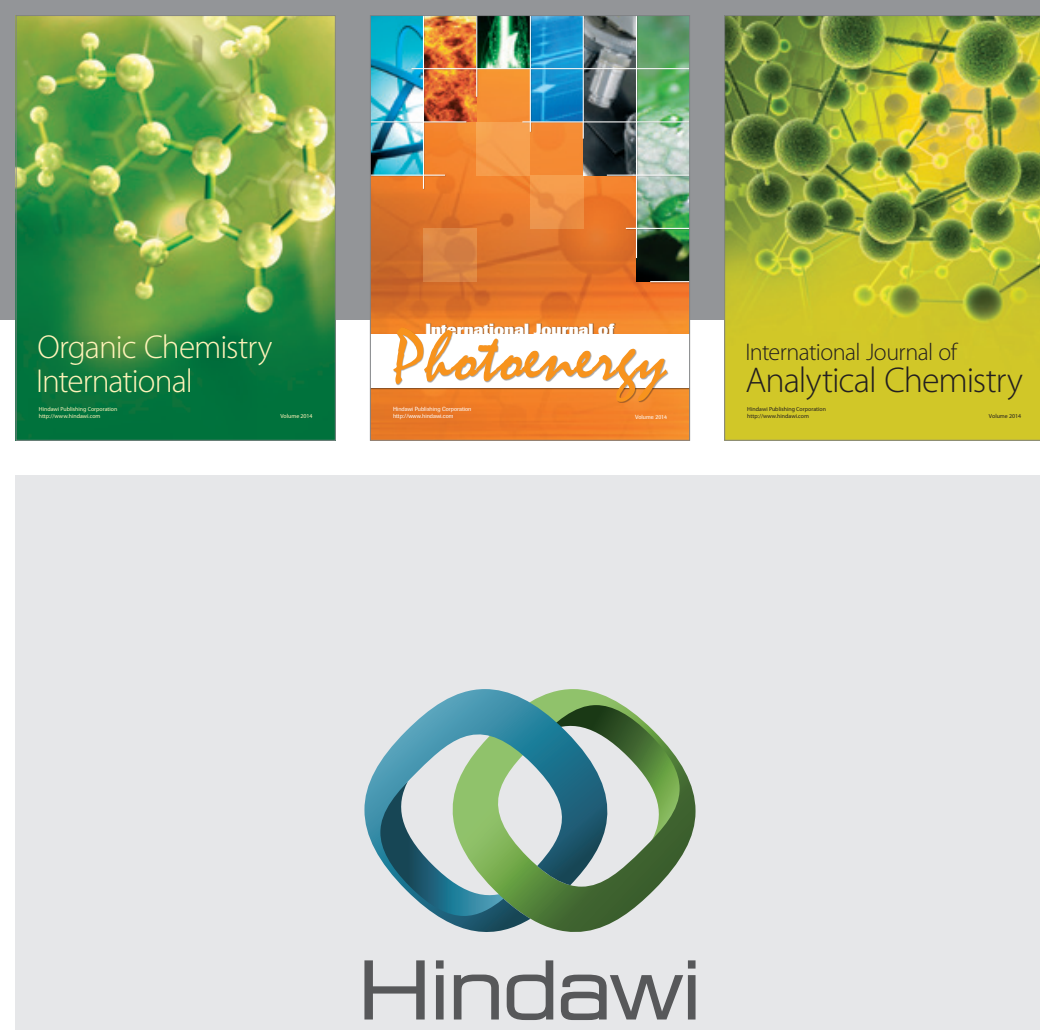

Submit your manuscripts at

http://www.hindawi.com
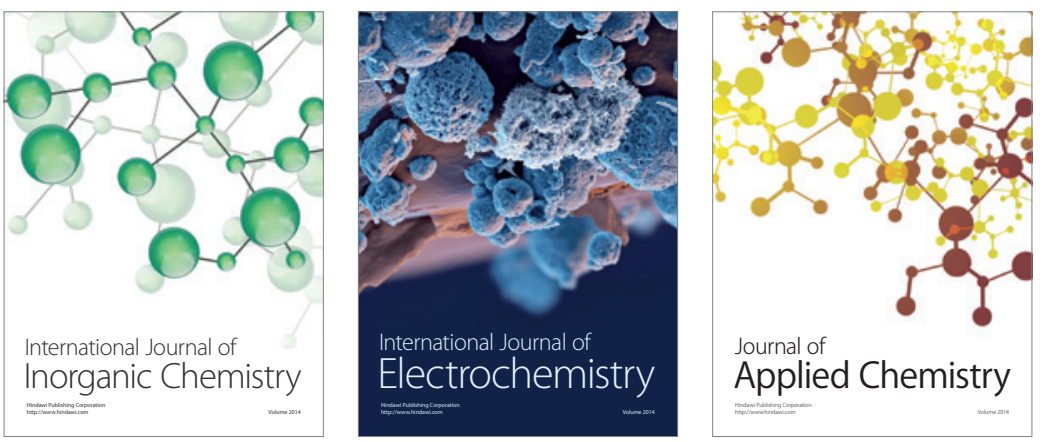

Journal of

Applied Chemistry
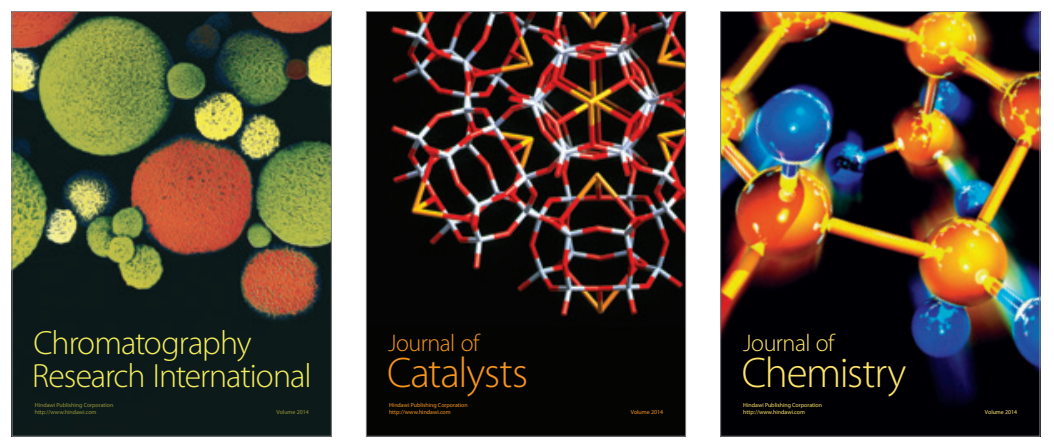
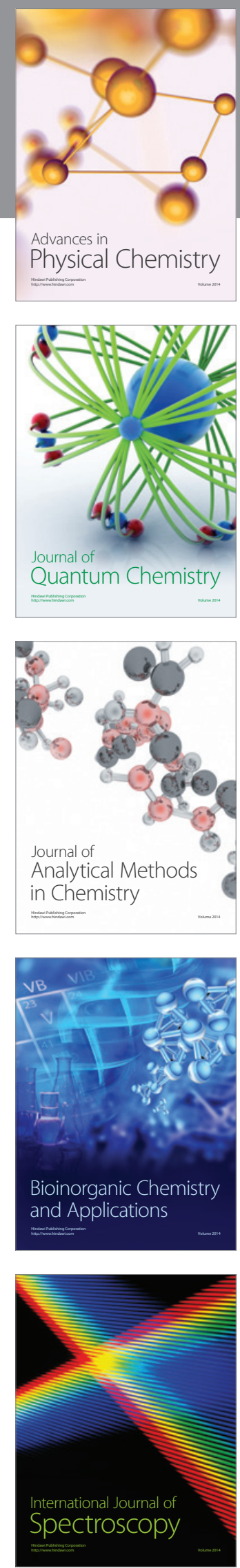